\title{
ETERNO RETORNO: BATAULT (1904), CIÊNCIA E TRANSVALORAÇÃO
}

\author{
Wilson Antonio Frezzatti Jr. \\ Universidade Estadual do Oeste do Paraná
}

\begin{abstract}
This paper examines the article "L'Hypothèse du Retour Éternel devant la science moderne" published by the Swiss philosopher Georges Batault in Revue philosophique de la France et de L'Etranger (1904). We intend to show that a scientific approach to the Nietzschean notion of eternal recurrence without its philosophical context turns it into a metaphysical concept. We can not understand properly the eternal recurrence without the project of the transvaluation of all values. The Nietzschean eternal recurrence is not a scientific theory, but a thought experiment, whose goal is to overcome the prevailing interpretation, namely the Christian-metaphysical interpretation.
\end{abstract}

Keywords: Eternal recurrence, metaphysics, Nietzsche, revue philosophique de la France et de l'Étranger, transvaluation of all values.

Resumo: Este texto investiga o artigo "L'Hypothèse du Retour Éternel devant la science moderne" do filósofo suíço Georges Batault, publicado em 1904 na Revue philosophique de la France et de l'Étranger. Pretendemos mostrar que uma abordagem científica da noção nietzschiana de eterno retorno sem considerar seu contexto filosófico transforma-a em uma concepção metafísica. Não podemos entender o eterno retorno desvinculado da proposta de transvaloração de todos os valores. O eterno retorno nietzschiano não é uma teoria científica, mas uma experiência do pensamento, cuja meta é superar a interpretação dominante, ou seja, a interpretação metafísico-cristã.

Palavras-chave: Eterno retorno, metafísica, Nietzsche, revue philosophique de la France et de l'Étranger, transvaloração de todos os valores.

A recepção de Nietzsche na França, no período da passagem do século $\mathrm{XIX}$ ao XX, tem como característica o destaque às questões morais. Algumas leituras destacam o imoralismo de Zaratustra e uma pretensa filosofia do 
individualismo, consideradas uma ameaça aos pilares da sociedade, a saber, a compaixão cristã e os liames da coletividade ${ }^{1}$. Os críticos não deixavam de associar essa ameaça à loucura. Entretanto, embora com menor destaque, questões acerca do conhecimento e da ciência também aparecem. Entre essas questões, o eterno retorno parece despertar mais interesse do que a vontade de potência. Apresentaremos, neste trabalho, a leitura de Georges Batault que tenta justificar cientificamente a proposta nietzschiana do eterno retorno: "A hipótese do eterno retorno frente à ciência moderna" (" $L$ 'Hypothèse du Retour Éternel devant la science moderne”, 1904). Mais importante do que investigar aspectos da recepção da filosofia nietzschiana por filósofos e cientistas franceses por volta de 1900, interessa-nos aqui estudar os resultados de se utilizar noções como o eterno retorno independentes de seu contexto filosófico. Refiro-me aos aspectos ligados à crítica contra a metafísica e à construção de uma filosofia que afirma a vida e o mundo como um movimento contínuo de autossuperação. Em outras palavras, interpretações como a de Batault transformam a filosofia de Nietzsche em mais uma hipótese metafísica, e expulsam seu movimento construtivo, em especial a transvaloração dos valores.

O material de nosso trabalho e das considerações gerais acima é oriundo da Revue philosophique de la France et de l'étranger. Esse periódico foi fundado em 1876 pelo filósofo e psicólogo Théodule Ribot para agregar as discussões em torno do estatuto da Psicologia e suas relações com as ciências naturais e a Filosofia, ou seja, divulgar uma "nova psicologia" (positivista e científica) em substituição à "velha psicologia” (espiritualista e metafísica) (cf. FREZZATTI 2010). A Revue durou até 1938 (126 números), com periodicidade semestral e com as seguintes seções: a) Artigos originais; b) Notas, discussões, documentos: assuntos específicos e pontuais, como, por exemplo, comentários de experimentos e teorias; c) Análises e relatos críticos (comptes rendus): resenhas de livros e artigos; d) Revisão de periódicos: os principais periódicos filosóficos e científicos eram listados; e) Principais artigos: alguns artigos listados na seção anterior recebiam uma resenha e um comentário crítico. Essa estrutura permitia que uma quantidade imensa de

\footnotetext{
${ }^{1} \mathrm{Na}$ Revue philosophique de la France et de l'étranger, temos, por exemplo, 0 artigo de Alfred Fouillée que critica o individualismo que entende estar presente na filosofia nietzschiana (FOUILLÉE 1901); e 0 artigo de Georges Palante que aponta alguns problemas no que chama de moral do além-do-homem (Palante 1900).
} 
informações e teorias fosse veiculada em cada número. Nietzsche conhecia o periódico e muito possivelmente foi através dele que conheceu ou teve sua atenção atraída para autores como: Ribot, Alexander Herzen (filho), Alfred Espinas, Alfred Fouillée, Charles Féré, Eduard von Hartmann, Émile Durkheim, Francis Galton, Charles Peirce, Gustave Le Bon, Herbert Spencer, Hyppolite Taine, Franz Brentano, Paul Littré, Cesare Lombrozo, entre muitos outros (cf. HAAZ 2002 e FREZZATTI 2010). Em uma carta a Paul Rée do início de agosto de 1877 e em outra a Malwida von Meysenbug de 04 de agosto do mesmo ano, Nietzsche fala da Revue philosophique. Na última carta, o filósofo alemão descreve: "eu estabeleci contato proveitoso com um inglês, Sr. G. Croom Robertson, e sua família; eu tenho dificuldade em ter que deixá-lo hoje. Ele é professor da University College of London, e é o editor do melhor periódico de filosofia (não somente da Inglaterra, mas em geral; no máximo, a revue philosophique de Th. Ribot lhe iguala” (Briefe 5, p. 268) ${ }^{2}$.

Nietzsche, no entanto, também foi apresentado aos leitores da revista de Ribot. A Revue philosophique não ficou imune à moda Nietzsche que ocorreu nos salões parisienses na virada do século XIX para o XX. Os números de 1892 a 1937 trouxeram dezenas de textos sobre a filosofia nietzschiana, em sua grande maioria relatos críticos de livros alemães e franceses ${ }^{3}$. Nesses relatórios, os autores das resenhas críticas posicionavam-se sobre o texto analisado e sobre a filosofia nietzschiana, havendo aqueles que a defendiam (por exemplo, Palante e Louis Weber) e aqueles que a rejeitavam (por exemplo, Fouillée e Arréat). Os próprios resenhistas argumentavam e contra-argumentavam entre si por meio das análises críticas. Temos, assim,

\footnotetext{
2 O professor Robertson é o primeiro editor da revista Mind. Na carta, Nietzsche diz que colaboram na revista "todos" os grandes filósofos ("Spencer, Tylor, Maine, Darwin, etc., etc.") e conta o interesse do inglês pelo livro de Rée, seu gosto por Wagner e a promessa de, se Nietzsche e Rée forem a Londres, apresentá-los a todas as "autoridades célebres". Sabe-se muito pouco sobre o encontro de Nietzsche com Robertson. Segundo Haaz (2002, p. 81, nota 176), talvez tenham lido e discutido Esboço biográfico de uma criança ( $A$ biographical sketch of an infant) de Charles Darwin.

3 Considerando apenas os anos em torno do artigo de Batault (1904), temos, por exemplo: Robert Schellwein. Max Stirner und Friedrich Nietzsche, Erscheinungen des modernen Geistes, und das Wesen des Menschen (1892) (Arréat 1892); Rudolf Steiner. Friedrich Nietzsche, ein Kampfer gegen seine Zeit (1895) (ARRÉAT, 1896); Grace Neal Dolson. The philosophy of Friedrich Nietzsche (1901) (ARRÉAT 1901); Pierre Laserre. La morale de Nietzsche (1902) (DAUDIN 1903); Francesco Orestano. Le idee fondamentali di F. nel loro progressivo svolgimento: esposizione e crítica (1903) (RIBOT 1903); Alfred Fouillée. Nietzsche et l'immoralisme (1902) (PALANTE 1903); Raoul Richter. Friedrich Nietzsche. Sein Leben und sein Werk (1903) (PALANTE 1905a); O. Ewald. Nietzsches Lehre in ihren Grundbegriffen. Die Ewige Wiederkunft des Gleichen und der Sinn des Übermenschen (1903) (PALANTE 1905b); Jules de Gautier. Nietzsche et la reforme philosophique (1904) (PALANTE 1905c).
} 
um perfil da recepção francesa de Nietzsche no período que vai de 1890 a 1937, podendo-se perceber um aumento e uma radicalização de sua rejeição na época da Primeira Guerra Mundial (1914-1918).

Georges Batault (1887-1963) é um filósofo, historiador e poeta suíço de expressão francesa, autor dos livros Quatro meditações sobre Nietzsche (Quatre méditations sur Nietzsche, 1909) e $O$ problema judaico. $O$ renascimento do antissemitismo (Le problème juif. La renaissance de l'antissemitisme, 1921). É também conhecido por suas obras nacionalistas e antissemitas e por suas polêmicas com Victor Hugo. No artigo de 1904 que iremos apresentar, publicado na Revue philosophique, Batault pretende dar uma fundamentação científica ao eterno retorno.

A noção de eterno retorno, segundo Batault, foi desenvolvida no século XIX, embora ela já apareça de forma imprecisa em autores antigos. Os três pensadores responsáveis pela noção contemporânea do eterno retorno são três: 1. Louis Auguste Blanqui: $A$ eternidade pelos astros ( $L$ 'éternité par les astres, 1871); 2. Gustave Le Bon: $O$ homem e as sociedades, tomo II ( $L$, homme et les sociétés, 1881); e 3. "o tão profundo e original filósofo" Friedrich Nietzsche ${ }^{4}$. O filósofo alemão teria sido quem mais e melhor desenvolveu essa ideia. Considerando que Nietzsche inicialmente pretendia dar uma base científica à sua teoria e que, logo em seguida, achou que isso era impossível, o filósofo suíço tem como objetivo mostrar que o autor de Assim falava Zaratustra estava enganado: a hipótese do eterno retorno é lógica e compatível com a ciência do início do século XX. Pelo simples fato de tratar o eterno retorno como uma hipótese, Batault reafirma sua posição de entender como científica essa noção nietzschiana.

O eterno retorno, proclama o próprio Nietzsche, foi pensado pela primeira vez em agosto de 1881 , em Surlei, na Suíça, como uma inspiração ${ }^{5}$ após a visão de uma pedra piramidal em um lago. A noção foi apresentada, segundo Batault, de forma muito breve e incompleta em $A$ gaia ciência (1882), de forma lírica em Assim falava Zaratustra (1883-85) e de forma

\footnotetext{
${ }^{4}$ Batault indica que Henri Lichtenberger, no apêndice de La philosophie de Nietzsche (1902), mostrou a relação entre esses três pensadores (cf. BATAULT 1904, p. 158).

${ }_{5}^{5}$ Para a noção de inspiração em Nietzsche, cf. EH/EH* Assim falava Zaratustra § 3.

(*): Adotaremos, nas citações das obras de Nietzsche, o padrão de abreviaturas adotado pelos Cadernos Nietzsche, originário da edição crítica das obras completas organizadas por Colli e Montinari (KSA): EH/EH - Ecce homo; FW/GC - Die fröhliche Wissenschaft (A Gaia Ciência). Para os fragmentos póstumos, indicaremos o fragmento e a data em que foi escrito de acordo com a edição Kritische Studienausgabe (KSA).
} 
científica em Vontade de potência (obra forjada por Elizabeth, irmã de Nietzsche, e lançada em 1901, com segunda edição em 1906) ${ }^{6}$. Já que a abordagem de Batault é autodenominada científica, ele se utiliza de Vontade de potência para apresentar o eterno retorno nietzschiano ${ }^{7}$.

Citando os aforismos 1062 e 385 da edição francesa de Vontade de Potência, traduzida por Henri Albert em 1903, (respectivamente, os fragmentos póstumos 36 [15] outono 1884 até outono 1885 e 38 [12] junhojulho 1885), Batault coloca, ao lado das ideias de que o mundo não tem começo nem fim e de que o mundo jamais cessará de vir a ser, a idéia de que a matéria é eterna. Em seguida, o autor suíço faz um resumo da doutrina do eterno retorno em seus aspectos que considera científicos. Inicia anunciando as premissas: as forças que constituem o Universo são eternas, e o tempo é infinito. Acredita serem lógicas do ponto de vista cosmológico as duas suposições de Nietzsche: 1 . Se as forças tivessem um fim, o mundo já não existiria, pois o tempo é infinito; e 2. as forças não podem aumentar indefinidamente, pois, o tempo sendo infinito, de onde viriam os elementos desse acréscimo? Uma hipótese, entretanto, parece ser problemática para Batault: para supor uma combinação sempre igual e infinita, é necessário admitir que um estado de equilíbrio nunca será atingido - justamente este é o pressuposto considerado arbitrário ${ }^{8}$. Entretanto, o autor acaba por justificar essa hipótese. Em primeiro lugar, sendo o tempo infinito, o equilíbrio já deveria ter sido atingido, caso fosse necessário que ele ocorresse. Em segundo lugar, levando em consideração que, no eterno retorno, as mesmas configurações repetem-se infinitas vezes na mesma ordem, se a primeira configuração do ciclo levasse ao equilíbrio no final, isso novamente já deveria

\footnotetext{
${ }^{6}$ Lembramos que, no projeto original do livro Vontade de potência, surgido por volta de agosto de 1885 , o subtítulo pretendido era "Ensaio de uma transvaloração de todos os valores". O eterno retorno, juntamente com a grande política, era um tema previsto para o quarto livro de Vontade de potência (cf. MARTON 2005, p. 21-24; 12 [2] início de 1888). Esse projeto era um entre outros e foi abandonado em meados de 1888, quando surge um novo projeto também em quatro livros: Transvaloração de todos os valores, cujo quarto livro intitulava-se "Dioniso - filosofia do eterno retorno". Ao final, o Anticristo acaba sendo considerado pelo próprio Nietzsche a efetivação desse projeto.

${ }^{7}$ De nossa parte, utilizaremos os fragmentos póstumos da edição crítica de Colli e Montinari (KSA) em vez dos aforismos de Vontade de potência citados por Batault.

8 Para não considerarmos esse pressuposto arbitrário, devemos ter claras as noções nietzschianas de força e de vontade de potência: não sendo materiais, as forças ou os impulsos são processos relacionais e não unidades últimas, são quanta de potência com uma tendência inelutável de crescimento. Chamamos a atenção para a argumentação de Batault: força e matéria não são distintas, ou seja, para ele, a matéria é força. Além disso, o autor desconsidera a vontade de potência, pois as forças são vistas como infinitesimais materiais e não como processos de aumento de potência.
} 
ter ocorrido. Assim, aceitando-se as suposições nietzschianas, a hipótese do eterno retorno torna-se um simples e imutável jogo matemático de combinações de um número imenso, mas finito, de átomos ${ }^{9}$. Para Batault, o núcleo central da hipótese do eterno retorno é a noção de átomo, mais exatamente uma certa noção de átomo, já que haveria diferentes noções.

Batault considera duas concepções básicas de átomo, isto é, do infinitamente pequeno: a dinamista e a mecanicista. Nietzsche é classificado como um dinamista. Enquanto os mecanicistas seguem Descartes, entendendo matéria como extensão, atributo essencial da substância corpo, os dinamistas vêem a matéria como força, no que estariam seguindo a alegada ideia kantiana de que a matéria é aquilo que é móvel no espaço. Para os dinamistas, a extensão é apenas um fenômeno. O filósofo suíço acredita que a hipótese do infinitamente pequeno está presente em todas as ciências particulares de sua época, embora ela mesma não possa ser provada. Essa presença, para Batault, faz parte de uma seqüência que alterna aceitação e rejeição da hipótese do atomismo: o atomismo de Demócrito, a época anti-atomista de Sócrates, o atomismo de Epicuro, etc. Esse desenrolar da história acerca da noção de átomo é utilizado pelo autor para indicar que há retornos secundários inseridos no grande movimento cósmico do eterno retorno. Não nos parece, entretanto, que haja no pensamento nietzschiano a proposta de retornos do mesmo secundários.

O filósofo suíço acredita que a ideia de átomo é inerente à própria ciência, o que faz que ele pretenda explicar o eterno retorno a partir do átomo do mesmo modo que ocorre com os fenômenos físicos e químicos. A tentativa de provar a lógica científica do eterno retorno repousa sobre dois pontos essenciais: 1. As teorias modernas dos infinitamente pequenos; e 2. As combinações matemáticas.

As teorias modernas dos infinitamente pequenos, segundo Batault, são quatro:

1. $\mathrm{O}$ infinitamente pequeno matemático; 2. $\mathrm{O}$ átomo químico; 3. $\mathrm{O}$ protoplasma biológico; e 4. O elétron físico. $\mathrm{O}$ infinitamente matemático é a base teórica de todos os outros, sendo, contudo, o menos útil para explicar o eterno retorno. A definição apresentada aproxima-se bastante daquela de limite: o

\footnotetext{
${ }^{9}$ Nesse momento do texto, Batault faz uma digressão propondo a pergunta: não haveria um eterno retorno atômico ou infinitesimal dentro do grande ciclo cósmico do eterno retorno? Ele pode fazer essa questão, a qual retomará adiante, pois aceita que as configurações podem se repetir várias vezes em um mesmo ciclo.
} 
infinitamente pequeno é atingido quando uma quantidade variável assume valores cada vez menores de tal modo que é menor que qualquer quantidade dada. Ele não é uma quantidade determinada, mas essencialmente variável que tem limite zero, ou seja, aproxima-se de zero por um valor infinitesimal. O infinitamente pequeno matemático não é um valor absoluto, mas relativo ${ }^{10}$.

A definição de átomo químico ou íon apresentada por Batault segue o verbete "Teoria atômica" do Dicionário de Química pura e aplicada (18691878, 1880-1886, 1892) do francês Charles-Adolphe Wurtz: átomos são partículas indivisíveis com peso invariável e movimento, sendo reunidas em combinações por afinidade. Esse tipo de infinitamente pequeno também tem importância na Física.

O protoplasma é o infinitamente pequeno na Biologia. Ele não é uma substância definida que tenha uma fórmula, e, igualmente à Química, que possui diferentes átomos, existem diferentes tipos de protoplasma que formam diferentes células. $O$ protoplasma não é uma unidade verdadeira, pois se divide em duas partes: o hialoplasma, claro e transparente, e o espongioplasma, translúcido e mais consistente. Além disso, a célula é tomada como uma unidade vital, da qual o protoplasma faz parte juntamente com o núcleo e a membrana. Há movimentos no protoplasma que produzem, como resultado, energia, que surge na forma de trabalho, calor, eletricidade, luz e influxo nervoso, dependendo do tipo de célula. A causa do movimento é a oxidação de substâncias protoplasmáticas, causada pelo oxigênio do ar, ou seja, os movimentos protoplasmáticos são fenômenos químicos. As substâncias do protoplasma são continuamente destruídas, gerando matéria inorgânica (desassimilação), mas, ao mesmo tempo, o protoplasma transforma matéria inorgânica em orgânica (nutrição). É o poder de transformar matéria inorgânica em orgânica que distingue o protoplasma dos seres inanimados: essa é a única diferença entre a vida e a morte.

Enquanto na Biologia a unidade infinitamente pequena (o protoplasma) é maior do que a da Química (o átomo ou íon), na Física ela é menor (o elétron físico). Batault, para escrever sobre o elétron, utiliza-se das teorias de William Crookes ${ }^{11}$ sobre a síntese de matéria. No início de tudo, a

\footnotetext{
10 Essa noção de relação, que poderia se aplicar a grosso modo à noção nietzschiana de impulso, ou seja, de quantum de potência, é descartada por Batault para explicar o eterno retorno.

11 William Crookes (1832-1919) foi um químico e físico inglês que realizou pesquisas nas áreas de análise espectral, eletricidade e radioatividade. Descobriu o elemento químico Tálio em 1861. Investigou
} 
matéria estaria em um estado de nuvem informe, pré-atômico e potencial: o chamado prótilo ${ }^{12}$, que seria constituído de cargas infinitamente pequenas de eletricidade. Essa carga, quando associada à matéria, foi chamada por Faraday de elétron. Os elétrons não são ondas etéreas nem formas de energia, mas substância dotada de inércia elétrica. Segundo Crookes, há um processo universal de dissociação atômica: o prótilo pode um dia retornar a ser a única forma existente. Batault cita Crookes: "e, então, o ponteiro das horas terá finalizado uma revolução sobre o mostrador da eternidade” (apud BATAULT 1904, p. 165). Se o infinitamente pequeno matemático é a base teórica de todos os átomos, o prótilo é a nebulosa sem forma de onde tudo sai e para onde tudo volta, incluindo também o íon, o protoplasma e o elétron.

Assim, Batault faz com que a doutrina do retorno seja inerente a uma certa concepção contemporânea de matéria. Mas há ainda uma conseqüência muito importante de sua abordagem: a noção de eterno retorno permite uma ligação possível entre a Metafísica e a Física. Com isso, chegaríamos mais perto em direção ao absoluto e à diminuição do número de ciências. A Metafísica, segundo o filósofo suíço, é o ramo mais especulativo e transcendente da Filosofia, e a hierarquia entre as ciências seria a seguinte: Psicologia, Biologia, Química e Física, sendo esta a superior. A meta é, por meio da doutrina científica do eterno retorno, transformar a Física em um ramo da Metafísica. Vejamos como.

O dinamismo, que considera que tudo é força, aceita a noção de tempo infinito, mas rejeita a de espaço infinito. Dessa forma, segundo Batault, o dinamismo está de acordo com a física contemporânea, que busca uma unidade de força para explicar todos os fenômenos e que quase provou a existência do infinitamente pequeno dotado de inércia, chamado elétron ${ }^{13}$. Essa mesma ciência mostra que os elétrons se ligam de diferentes maneiras,

também o espiritismo, acreditando numa força utilizada por inteligências superiores aos seres humanos e presente na comunicação com os espíritos.

12 Prótilo: termo formado pelas palavras gregas proto (primeiro) e hýle (matéria). Em Crookes, significa a matéria primeira homogênea, anterior ao surgimento e à evolução dos átomos. Em termos atuais, 0 prótilo se aproxima do que os físicos chamam de plasma.

13 John Joseph Thomson, em 1897, por meio de experimentos em tubos de raios catódicos, identificou uma partícula carregada negativamente em raios emitidos no vácuo, o elétron. Sua aceitação como constituinte dos átomos não foi imediata, mas várias propriedades foram matematicamente definidas: sua massa em relação ao átomo de hidrogênio era de 1/700 e tinha aproximadamente 2/3 da velocidade da luz. O modelo atômico que deu desenvolvimento à Física atômica e a mecânica quântica no século XX foi estabelecido apenas em 1911 por Ernest Rutherford. 
até formar as diferentes substâncias, as quais se dissociam e lançam ao espaço fragmentos de matéria. Tudo tende a voltar à nebulosa primitiva sem forma (o prótilo), na qual existe eternamente a mesma quantidade total de força. Aqui exatamente, ainda segundo Batault, situa-se o limite da Física e começa a Metafísica, mais especificamente a Cosmologia Racional14: no umbral, posta-se "a noção grandiosa do eterno retorno das coisas e das pessoas" (BATAULT 1904, p. 166).

Eis a hipótese do eterno retorno segundo Batault: o mundo, para a doutrina científica do eterno retorno, é composto de um número limitado, mas imenso, de átomos ou elétrons. Porque esse número é finito, as mesmas combinações, ao fim de um número imenso de anos, necessariamente repetirse-ão na mesma ordem. É possível que as mesmas combinações parciais se reproduzam muitas vezes, o que explica os retornos secundários, como, por exemplo, as doutrinas atomistas. Em um mundo constituído de forças, as combinações devem se seguir de forma encadeada, sendo que uma combinação não é seguida por uma qualquer, mas por uma bem definida. Isso ocorre inúmeras vezes até que se retorne, após um longo tempo, à primeira combinação que iniciou a seqüência. Conclusão de Batault: considerando-se as mais recentes hipóteses, um único sistema cosmológico é possível - o eterno retorno. Em outras palavras, sendo o tempo infinito e o número de infinitamente pequenos finito, os mesmo sistemas de combinação devem se reproduzir necessariamente.

$\mathrm{Na}$ apresentação da noção científica do eterno retorno, Batault faz uma ressalva: Nietzsche não teria se manifestado sobre os inúmeros retornos da matéria cósmica ao estado de prótilo antes de atingir a primeira combinação da série. Embora o prótilo possa ser produzido por diferentes combinações, necessariamente a combinação inicial deve ser o prótilo. $\mathrm{O}$ filósofo suíço, no entanto, não leva às últimas conseqüências a ressalva, pois afirma ser provável que Nietzsche tenha pensado nas várias repetições do prótilo, embora não houvesse explicitado isso. Percebamos que o autor não se refere à vontade de potência e não discute a presença ou não do prótilo na filosofia nietzschina, o que nos leva a pensar que Batault entende a noção

\footnotetext{
${ }^{14} \mathrm{Na}$ Crítica da razão pura de Kant, na Dialética transcendental, apresenta-se a Cosmologia racional que procura dar respostas às questões sobre o Universo, sem 0 apoio seguro de juízos sintéticos a priori. Como resultado, temos quatro antinomias, das quais a terceira é a mais importante para a Razão prática: sobre a existência ou não de uma causa livre. Será que Batault pensa ter resolvido as antinomias da Cosmologia racional através do eterno retorno?
} 
nietzschiana de força como tributária da noção de prótilo, já que classifica Nietzsche como um dinamista.

Antes de avaliarmos o impacto de uma leitura científica do eterno retorno nietzschiano sobre a transvaloração dos valores, falemos um pouco sobre essa própria noção. Em linhas gerais, podemos dizer que o projeto nietzschiano de transvaloração de todos os valores (Umwerthung aller Werthe) consiste em fundar os valores em outras bases distintas das tradicionais - metafísicas e religiosas (cf. MARTON 2006, p. 55). Os valores, isto é, as tábuas de bem e mal, são produzidos pelo próprio homem de acordo com suas condições históricas e fisiológicas (dinâmica impulsional dos impulsos em luta por mais potência) e não são eternos, absolutos e criados por entidades divinas ou divinizadas, tais como a Razão, aguardando serem revelados ou desvelados. Com a crítica aos valores transcendentes e, mais ainda, com a crítica ao fundamento desses valores, o homem pode atingir a condição do niilismo radical: a total ausência de sentido da existência humana. Para atravessar esse deserto, o homem deve criar valores sob novas bases. Entendemos que a noção de eterno retorno (ewige Wiederkunft), juntamente com, a nosso ver, sua inseparável companheira complementar, ou seja, a doutrina da vontade de potência (Wille zur Macht), exerce um papel axial na construção de não apenas uma nova base, mas de uma base antagonista àquela dos valores metafísico-cristãos.

Parece-nos que o livro de Rubira (2010), Nietzsche: do eterno retorno do mesmo à transvaloração de todos os valores, como o próprio autor tem consciência (RUBIRA 2010, p. 22), vem cobrir uma lacuna na pesquisa sobre Nietzsche: a relação intrínseca entre o pensamento do eterno retorno e a tarefa da transvaloração. O texto de Batault é mais um exemplo, em seu caso, precoce, da total desconsideração dessa relação. Aqui não desenvolveremos os problemas que o eterno retorno acarreta à transvaloração de todos os valores, como, por exemplo: "qual o sentido da realização da transvaloração, já que o retorno traz de volta a valoração metafísico-cristãe” (cf. Rubira 2010, p. 25). Nem abordaremos o papel que o amor fati exerce na relação em questão. Esses temas foram muito bem conduzidos em Rubira (2010). Nosso trabalho se aterá à simples desvinculação entre o eterno retorno e a transvaloração, produzida por entender-se a doutrina do eterno retorno como científica ou metafísica. Devemos fazer outro alerta aqui: a nossa análise não desconsidera a importância das leituras científicas de Nietzsche na construção do pensamento 
do eterno retorno. Elas foram muito importantes, mas isso não significa que devemos ver o eterno retorno nietzschiano como uma teoria científica.

Devemos, para que possamos cumprir nosso objetivo, apoiar-nos sobre uma interpretação do eterno retorno. Queremos aqui entendê-lo enquanto "experimento do pensamento", como sugere Marton (1992). Em outras palavras, o pensamento do eterno retorno é produto de um modo de filosofar que faz ensaios ou experimentos com o pensar e aborda uma ideia de várias e diferentes perspectivas. Aliás, achamos que um olhar muito míope sobre o perspectivismo nietzschiano é o responsável pela impressão de que o eterno retorno é uma teoria científica. Nietzsche apresenta sua filosofia experimental no fragmento póstumo 16 [32] primavera-verão 1888:

Uma filosofia experimental [Experimental-Philosophie], tal como eu a vivo, antecipa experimentalmente [versuchsweise] até mesmo as possibilidades do niilismo radical; sem querer dizer com isso que ela se detenha em uma negação, no não, em uma vontade de não. Ela quer, em vez disso, atravessar até o inverso - até a um dionisíaco dizer-sim ao mundo, tal como é, sem desconto, exceção e seleção [Auswahl] (tradução cf. MARTON 1992, p. 207).

O eterno retorno do mesmo é um experimento do pensamento que afirma a existência em suas mudanças, em suas alegrias e tristezas, sem o apoio de significados transcendentes ou imanentes. Assim, o eterno retorno não deve ser construído a partir das mesmas fundações da ciência e da metafísica criticadas pelo filósofo alemão. O eterno retorno constitui uma terceira via que evita as explicações teleológicas e as mecanicistas: o mundo é um eterno vir-a-ser que não teve início e não terá fim, é um processo e não uma estrutura estável (cf. MARTON 1992, p. 214).

Parece quase certo que a doutrina do eterno retorno não se sustenta cientificamente, havendo inúmeras dificuldades: da proposição "em um tempo infinito, cada combinação possível estaria alguma vez alcançada; mais ainda: estaria alcançada infinitas vezes" 15 não se segue necessariamente que "entre cada combinação e seu retorno todas as combinações ainda possíveis teriam de estar transcorridas" e, tampouco, que "cada uma das combinações

${ }^{15}$ Frases extraídas do fragmento póstumo 14 [188] primavera 1888. 
condiciona a sequência inteira das combinações da mesma série"; da repetição dos acontecimentos não se pode deduzir a repetição da série na mesma ordem; não é necessário que uma configuração só retorne depois de finda toda a série (Batault aceita e incorpora essa objeção); não é necessário que uma configuração determine a próxima (cf. MARTON 1992, p. 212). Há ainda outras dificuldades: a) nas configurações de forças, Nietzsche trata as quantidades de potência como se assumissem valores discretos, ou seja, números inteiros. Se a potência pudesse ser traduzida por números reais, ou seja, se a potência pudesse assumir valores de um conjunto infinito, a série de combinações não poderia ser finita. Nada indica ou define em que escala de quantidades um quantum de potência pode variar. Ao contrário do que afirma Batault, a análise combinatória sozinha não dá conta desse problema, pois as combinações de sequência de letras não levam em conta a quantidade de potência de cada letra; e b) Nietzsche, nas versões cosmológicas do eterno retorno, considera que o número total de forças é imenso, mas finito. No entanto, o filósofo alemão não segue esse pressuposto. Qualquer objeto da investigação psicofisiológica nietzschiana é constituído por uma configuração de forças: desde os seres inorgânicos, passando pelas mais ínfimas partes dos organismos vivos, até as culturas. Qualquer conjunto de impulsos pode ser dividido em subconjuntos ou, ao menos, interpretado como se não tivesse elementos últimos. Dessa forma, Nietzsche parece atuar em suas investigações como se as configurações não tivessem limite para as subdivisões.

O eterno retorno, entendido como experiência do pensamento, tem como meta superar a interpretação dominante, ou seja, a interpretação metafísico-cristã. Como lemos no fragmento póstumo 9 [8] outono 1887: "No lugar da metafísica e da religião, a doutrina do eterno retorno (como meio de seleção [Züchtung] e escolha)". Em outro fragmento póstumo (2 [70] outono 1885 / outono 1886), Nietzsche relaciona vários temas para uma possível continuação de Além de bem e mal: "Interpretação, não conhecimento. Pela teoria do método. O eterno retorno". Trata-se de uma interpretação antagonista à metafísica das dualidades qualitativas opostas e absolutas. E, no pensamento nietzschiano, a interpretação tem um caráter estético, ou seja, já que não há verdades absolutas, o homem é criador dos conceitos e não seu desvelador.

Em Gaia ciência $\S 341$, ao apresentar o eterno retorno do mesmo, Nietzsche faz um desafio ao leitor após as últimas palavras do demônio, que foram as seguintes: "A eterna ampulheta da existência será sempre virada outra vez - e tu com ela, poerinha da poeira!”. O desafio é posto nas seguintes palavras: 
Não te lançarias ao chão e rangeria os dentes e amaldiçoaria o demônio que te falasse assim? Ou viveste alguma vez um instante descomunal, em que lhe responderias: "Tu é um deus, e nunca ouvi nada mais divino!".

Se esse pensamento adquirisse poder sobre ti, assim como tu és, ele te transformaria e talvez te triturasse; a pergunta, diante de tudo e de cada coisa: "Quero isto ainda uma vez e ainda inúmeras vezes?" pesaria como o mais pesado dos pesos sobre teu agir! Ou então, como terias de ficar de bem contigo mesmo e com a vida, para não desejar nada mais do que essa última, eterna confirmação e chancela? (Tradução cf. Rubens R. Torres Filho in: NIETZSCHE 1978, p. 208-209)

Vivenciar o pensamento do eterno retorno: ressaltamos que vivenciar não significa aceitar voluntariamente ou ser convencido por argumentação racional. Considerá-lo como algo "divino" e "não desejar nada mais do que essa eterna confirmação” pressupõe uma saúde impulsional: impulsos potentes e altamente hierarquizados. Como diz Nietzsche: "o simples fato de a moral ser sentida como superada pressupõe um grau apreciável de cultura espiritual [geistiger Cultur] e esta é, por sua vez, um relativo bem estar [Wohlleben]" (5 [71] verão 1886 / outono 1887). No mesmo excerto, o filósofo afirma que a doutrina do eterno retorno também pressupõe essas condições. É preciso haver potência suficiente para prescindir dos consolos metafísicos e viver criando os próprios significados para a vida. Significados que não são verdades absolutas sobre a realidade, pois o conhecimento em si é impossível no vir-a-ser (cf. FREZZATTI 2006, p. 282-285). Para Nietzsche, o conhecimento só é possível como "erro sobre si próprio, como vontade de potência, como vontade de ilusão” (7 [54] final de 1886 / primavera 1887). Um erro impõe-se como verdade porque é uma perspectiva resultante da luta entre impulsos por mais potência que domina todas as outras. Para manter suas condições de crescimento, uma configuração de impulsos mobiliza todos aqueles dominados, dando-se um caráter absoluto: essa situação produzida pelo jogo agonístico e dinâmico das forças, impondo-se como perspectiva verdadeira, é um erro provisório, pois outra configuração imporá outra "verdade", isto é, um outro erro provisório. Sendo assim, para Nietzsche, a construção de perspectivas só pode ter um caráter estético: 
Vir-a-ser enquanto inventar, querer, autonegação, auto-superação: nenhum sujeito, porém um fazer, estabelecer, criador, nenhum "causas e efeitos". A arte enquanto vontade de superar o vir-a-ser, enquanto "eternizar", porém míope, sempre ligado à perspectiva: reproduzindo, por assim dizer, no pequeno a tendência do todo (7 [54] final de 1886 / primavera 1887).

Em outras palavras, vontade de potência e eterno retorno no lugar dos conceitos metafísicos, pois eles conseguem "eternizar" sem imobilizar. O eternizar estético de Nietzsche não cria valores eternos e absolutos, mas incide sobre o efêmero, sobre o instante: o momento se repetiu infinitas vezes e repetir-se-á outras infinitas vezes. É dessa forma que entendemos que o eterno retorno funciona como um martelo (cf. fragmento póstumo 5 [70] verão 1886 / outono 1887): a demolição da metafísica e dos valores tradicionais que sufocam as múltiplas potências criativas humanas; e, além disso, a abertura para a experimentação de novos pensamentos.

O martelo demole também a ideologia do progresso, que projeta para o futuro um estado de perfeição. Uma cultura, segundo o filósofo alemão, não deve durar o máximo possível, mas deve ter como meta ser o máximo possível breve e elevada: a única forma durável para a humanidade é viver em ciclos (cf. fragmento póstumo 2 [5] verão-outono 1882), nos quais em cada um impera um aspecto do humano que dá lugar a outro após o seu esgotamento. Afirma Nietzsche: "critério da força: poder viver segundo as apreciações de valor inversas e novamente as querer eternamente” (9 [1] outono 1887). Essa eternidade só pode ser vivenciada com as experiências de pensamento do eterno retorno e da vontade de potência:

Princípios e considerações antecipadas:

Para história do niilismo europeu.

Enquanto conseqüência necessária dos ideais prevalentes até agora: ausência absoluta de valor.

A doutrina do eterno retorno: enquanto sua conclusão, enquanto crise.

$[\ldots]$

4. O problema da vida: enquanto vontade de potência. 
(Preponderância temporária dos sentimentos sociais de valor, compreensível e útil: trata-se do estabelecimento de uma infraestrutura sobre a qual torna-se enfim possível uma espécie mais forte) (Fragmento póstumo XII 9[1] do outono de 1887).

A vontade de potência tem um caráter eterno por constituir uma luta infinita entre impulsos por mais potência, um jogo de impulsos que tendem a nunca se cristalizar. O eterno retorno, por ser cíclico.

Pensamos que, com o que dissemos acima, torna-se clara a indissociação entre eterno retorno, vontade de potência e transvaloração de todos os valores. Entender o eterno retorno como uma teoria científica que descreve a realidade do mundo é quebrar esse vínculo e desconsiderar a própria filosofia nietzschiana. Considerar as forças nietzschianas, ou seja, os quanta de potência que se efetuam como tendência a crescimento, como elementos últimos, sejam eles átomos materiais ou forças físicas, significa passar por cima da tentativa nietzschiana de superar as dualidades metafísicas, inclusive a dualidade matéria - energia. Nietzsche declara sobre a ciência que busca elementos últimos:

A ciência mesma se funda sobre uma crença, ela não é ciência "sem pressuposição". [...] Essa vontade de verdade: o que é ela? É a vontade de não se deixar enganar? [...] Mas por que não enganar? Mas por que não se deixar enganar? [...] De onde a ciência tomou sua crença absoluta, sua convicção sobre a qual repousa, a saber, que a verdade é mais importante que qualquer outra coisa, até mesmo que qualquer outra conviç̧ão? [...] é ainda e sempre sobre uma crença metafísica que repousa nossa crença na ciência, - [...] nós que buscamos hoje o conhecimento, nós, os sem-deus e antimetafísicos, nós acendemos ainda nosso fogo na fogueira que uma crença milenar inflamou, essa crença cristã que foi também a de Platão, a crença de que Deus é a verdade, que a verdade é divina... (FW/GC § 344).

A manutenção das dualidades metafísicas (verdade/falsidade, bem $/ \mathrm{mal}$, alma/corpo, divino/humano, cultural/biológico, etc.) bloqueia a transvaloração de todos os valores, pois a superação do próprio dualismo, e não a simples valorização de um polo em detrimento do outro, é a meta nietzschiana e o pressuposto para a construção de um outro modo de pensar. Além disso, a 
desconsideração do projeto da transvaloração e leituras descontextualizadas do eterno retorno permitem interpretações cientificistas da filosofia nietzschiana e apropriações indevidas, tais como a nazista e a eugenista.

\section{Referências bibliográficas}

ARRÉAT, L. Compte Rendu: Robert Schellwein. Max Stirner und Friedrich Nietzsche, Erscheinungen des modernen Geistes, und das Wesen des Menschen. Leipzig: Pleffer, 1892. In: Revue philosophique de la France et de I'étranger, Paris, 34: 331-335, 1892.

. Compte Rendu: Rudolf Steiner. Friedrich Nietzsche, ein Kampfer gegen seine Zeit. Weimer: E. Felker, 1895. In: Revue philosophique de la France et de l' étranger, Paris, 41: 463-464, 1896.

. Compte Rendu: Grace Neal Dolson. The philosophy of Friedrich Nietzsche. New York: Macmillan, 1901. In: Revue philosophique de la France et de l'e étranger, Paris, 52: 330-331, 1901.

BATAULT, G. "L'Hypothèse du Retour Éternel devant la science moderne”. In: Revue philosophique de la France et de 1' étranger, Paris, 58: 158-167, 1904.

DAUDIN, H. Compte Rendu: Pierre Laserre. La morale de Nietzsche. Paris: Mercure de France, 1902. In: Revue philosophique de la France et de l'étranger, Paris, 55: 110-112, 1903.

FOUILLÉE, A. "Les jugements de Nietzsche sur Guyau d'après des documents inédits". In: Revue philosophique de la France et de l' étranger, Paris, 52: 569-599, 1901.

FREZZATTI Jr., W. A. A fisiologia de Nietzsche: a superação da dualidade cultura/biologia. Ijuí: UNIJUÍ, 2006.

. "Nietzsche e Théodule Ribot: Psicologia e superação da metafisica". In:

Natureza Humana, São Paulo, v. 12, n. 2, 2010. p. 1-28. (Ed. on-line: http://www.winnicottnaturezahumana.com.br/modules/mastop_publish/?tac=44) HAAZ, I. Les conceptions du corps chez Ribot et Nietzsche à partir des Fragments posthumes de Revue philosophique de la France et de 1' étranger et de la Recherche-Nietzsche. Paris: L' Harmattan, 2002.

MARTON, S. "O eterno retorno do mesmo: tese cosmológica ou imperativo ético?”. In: NOVAES, Adauto (org). Ética. São Paulo: Companhia das Letras, 1992. p. 205-223.

. Desfigurações e desvios. In: MARTON, Scarlett (org). Nietzsche na Alemanha. São Paulo / Ijuí: Discurso / Unijuí, 2005. p. 13-49 
. A transvaloração dos valores. $2^{\circ}$ ed. São Paulo: Moderna, 2006.

NIETZSCHE, F. W. Obras incompletas. Tradução: Rubens R. Torres Filho. São Paulo: Abril Cultural, 1978 (Os pensadores).

. Sämtliche Briefe. Kritische Studienausgab. Berlin/New York: Walter de Gruyter, 1986. 8 Bd.

. Sämtliche Werke. Kritische Studienausgab. G. Colli und M. Montinari (Hg). Berlin: Walter de Gruyter, 1999. 15 Bd

PALANTE, G. "Le dilettantisme social et la philosophie du 'surhomme". In: Revue philosophique de la France et de l' étranger, Paris, 50: 614-624, 1900.

. Compte Rendu: Alfred Fouillée. Nietzsche et l'immoralisme. Paris: Alcan, 1902. In: Revue philosophique de la France et de l' étranger, Paris, 56: 93103, 1903.

. Compte Rendu: Raoul Richter. Friedrich Nietzsche. Sein Leben und sein Werk. Leipzig: Verlag, 1903. In: Revue philosophique de la France et de 1' étranger, Paris, 59: 314-317, 1905a.

. Compte Rendu: O. Ewald. Nietzsches Lehre in ihren Grundbegriffen. Die Ewige Wiederkunft des Gleichen und der Sinn des Übermenschen. Berlin: E. Hofmann, 1903. In: Revue philosophique de la France et de l' étranger, Paris, 59: 323-325, $1905 \mathrm{~b}$.

- Compte Rendu: Jules de Gautier. Nietzsche et la reforme philosophique. Paris: Mercure de France, 1904. In: Revue philosophique de la France et de l' étranger, Paris, 60: 660-664, 1905c.

RIBOT, T. Compte Rendu: Francesco Orestano. Le idee fondamentali di F. nel loro progressivo svolgimento: esposizione e crítica. Palermo: Reber, 1903. In: Revue philosophique de la France et de l' étranger, Paris, 55: 453-457, 1903.

RUBIRA, L. Nietzsche: do eterno retorno do mesmo à transvaloração de todos os valores. São Paulo: Discurso Editorial / Editora Barcarolla, 2010. 